DOI 10.37882/2500-3682.2021.09.02

\title{
КОНЦЕПЦИЯ ОБЩЕНИЯ В СУБЪЕКТ-ОБЪЕКТНОМ РАЗДЕЛЕНИИ БЫТИЙСТВЕННОСТИ И ЕЕ АКТУАЛЬНОСТЬ В СОВРЕМЕННОЙ КОММУНИКАТИВНОЙ ДЕЙСТВИТЕЛЬНОСТИ (НА МАТЕРИАЛАХ ТРУДОВ ПАВЛА АЛЕКСАНДРОВИЧА ФЛОРЕНСКОГО И КАРЛА ЯСПЕРСА)
}

\section{THE CONCEPT OF COMMUNICATION IN THE SUBJECT-OBJECT DIVISION OF BEINGNESS AND ITS RELEVANCE IN MODERN COMMUNICATIVE REALITY (BASED ON THE WORKS OF PAVEL ALEXANDROVICH FLORENSKY AND KARL JASPERS)}

\section{O. Bagaeva}

Summary: The subject of this research is the process of communication, communication in a situation of dividing beingness into an object and a subject in the context of a transforming communicative reality. The object of the work is the reflections of Karl Jaspers and P.A. Florensky on the problem of communicative studies in a social and humanistic orientation, in a strong belief in the spiritual development of each person. In the writings of thinkers, the theme of loneliness and phenomena that can overcome it arise. The antagonism of loneliness and friendship, loneliness and love, Ioneliness and deep communication sometimes plays a significant role in the reflections of Jaspers and P.A. Florensky, perhaps because the problem of interaction between man and the world, the subject and the outside world is one of the cornerstones of modernity. Object: The aim of this analysis of the philosophical views of Karl Jaspers and P.A. Florensky is to study the views of thinkers about the essence of communication, its importance in the context of modern communicative transformation. It seems relevant, it is necessary to understand the meaning of the teachings of $K$. Jaspers and P.A. Florensky about communication in the present period, when there is an urgent need for the formation of new methods of communication.

Methods: The methods of this research are the historical-philosophical approach, presented by the methods of analysis in the form of comparison comparison, generalization of research data and drawing conclusions. Also methods of reconstruction, concrete historical, hermeneutic and comparative methods were used.

Findings: Reflections of Karl Jaspers and P.A. Florensky about communication are of value not only for a philosophical analysis of the spiritual state of a person, especially those who are experiencing an essential crisis, but also for the real formation of those forms of communication in social interaction that are characteristic of individuals, remain faithful to their distinctive cultural and essential heritage in alienated, technocratic and consumer times.

Conclusions: The main conclusion of the study is the statement of Karl
Багаева Ольга Николаевна

К.ф.н., дочент, ФГБОУ ВО «Нижегородский государственный лингвистический университет им. Н.А. Добролюбова» olga_bagaeva1@yahoo.com

Аннотация: Предметом данного исследования является процесс общения, коммуникации в ситуации разделения бытийственности на объекта и субъекта в условиях трансформирующейся коммуникативной реальности. В качестве объекта работы выступает размышления Карла Ясперса и П.А. Флоренского над проблемой коммуникативистики в социальной и гуманистической ориентации, в крепкой вере в духовное развитие каждого человека. В трудах мыслителей возникает тема одиночества и явлений, которые могут преодолеть его. Антагонизм одиночества и дружбы, одиночества и любви, одиночества и глубокого общения подчас занимает весомую роль в размышлениях Ясперса и П.А. Флоренского, может быть, потому что, проблема взаимодействия человека и мира, субъекта и внешнего мира является одной из краеугольных тем современности.

Цель (0bject): Целью данного анализа философских взглядов Карла Ясперса и П.А. Флоренского является изучение взглядов мыслителей о сущности коммуникации, ее важности в условиях современной коммуникативной трансформации. Представляется актуальным, необходимым понимать смысл учения К. Ясперса и П.А. Флоренского о коммуникации именно в настоящий период, когда наблюдается острая необходимость в формировании новых способов коммуницирования.

Методы (Methods): Методами данного исследования служит историко-философский подход, представленный приемами анализа в форме сопоставления, сравнения, обобщения исследовательских данных и построения выводов. Также использованы методы реконструкции, конкретно-исторический, герменевтический и компаративистский методы.

Результаты (Findings): Размышления Карла Ясперса и П.А. Флоренского 0 коммуникации представляют ценность не только для философского анализа духовного состояния человека, в особенности - переживающего сущностный кризис, но и для реального формирования тех форм общения в социальном взаимодействии, которые свойственны личностям, сохраняющих верность самобытному культурному сущностному наследию в отчуждённые, технократические и потребительские времена.

Выводы (Conclusions): Основным выводом проведенного исследования является утверждение Карла Ясперса и П.А. Флоренского о том, что предпосылкой существования сегодняшнего миропорядка, взятого в глубине, является характер бытия человеческой личности и его способность вступать в глубокие коммуникативные отношения с «Другим», что может быть сложностью в условиях изменения характера коммуникативной ситуации в настоящем. Вкладом автора в исследование темы является анализ рассматриваемого вопроса в переложении его на современные коммуникативные особенности. Новизна исследования заключается в подробном анализе философских раз- 
Jaspers and P.A. Florensky that the precondition for the existence of today's world order, taken in depth, is the nature of the human personality and its ability to enter into deep communicative relations with the "Other», which can be difficult in the face of changes in the nature of the communicative situation in the present. The author's contribution to the study of the topic is the analysis of the issue in question in its transposition into modern communicative features. The novelty of the research lies in a detailed analysis of the philosophical reflections of Karl Jaspers and P.A. Florensky regarding this topic and the identification of the importance of the problem of dialogicity as the most important human property in the era of communication transformation.

Keywords: alienation, dialogue, brotherhood, dialogism, unity, communication, Florensky, Jaspers, philosophy of communication, Ioneliness, individualization.

\section{Введение}

Глубокая трансформация социальной реальности в современной России вызывает коренные изменения в коммуникативной сфере. Человек современности ищет новые социокультурные, философские, сущностные основания, способные обеспечить коммуникацию новой формации. Новая коммуникативная среда активно формируется, предлагается через СМИ и СМК. Стремясь утвердить собственные жизненные ценности, смыслы индивид воспринимает мультикультурный, полисемантичный код как неподлинную (несобственную) коммуникацию и пытается противостоять унификации, устанавливая коммуникацию подлинную, самостную. Этот процесс, характерный для ситуации мировоззренческого, смыслового плюрализма, приводит к формированию специфической коммуникационной среды, чье изучение становится сверхактуальной целью.

Материалы и методы: В данном исследовании использовались труды Павла Александровича Флоренского и Карла Ясперса, а так же работы современных исследователей философского творчества указанных мыслителей (Власова О.А., Водолагин А.В., ЗолотухинаАболина Е.В., Марков, Б.В.). Методами данного исследования служит историко-философский подход, представленный приемами анализа в форме сопоставления, сравнения, обобщения исследовательских данных и построения выводов. Также использованы методы реконструкции, конкретно-исторический, герменевтический и компаративистский методы.

Литературный обзор: В данном исследовании использовались труды Павла Александровича Флоренского (и Карла Ясперса, а так же работы современных исследователей философского творчества указанных мышлений Карла Ясперса и П.А. Флоренского относительно данной тематики и выявлении важности проблемы диалогичности как важнейшего свойства человека в эпоху коммуникационной трансформации.

Ключевые слова: отчуждение, диалог, братство, диалогичность, единение, коммуникация, Флоренский, Ясперс, философия общения, одиночество, индивидуализация.

мыслителей (Власова О.А., Водолагин А.В., ЗолотухинаАболина Е.В., Марков, Б.В.).

\section{Обсужкение}

В трудах многих философов возникает тема одиночества и явлений, которые могут преодолеть его. Антагонизм одиночества и дружбы, одиночества и любви, одиночества и братства подчас занимает весомую роль в размышлениях многих мыслителей, может быть, потому что, проблема взаимодействия человека и мира, субъекта и внешнего мира является одной из краеугольных тем жизнедеятельности человечества, которая не имеет временных характеристик.

Предпосылкой существования сегодняшнего миропорядка, взятого в глубине, по мнению Карла Ясперса, является характер бытия человеческой личности. Если индивид отсутствует в качестве экзистенциально наполненного субъекта, а является, по словам И.Н. Сидорова, «декоративно небрежной представленностью» [9, с.77], то на первый план выступает по большому счету бесполезность пребывания человека в этом мире. Задача, стоящая перед любой личностью, заключается в том, чтобы не погрязнуть в естественном желании механически продолжать, иначе говоря, влачить свое существование, постоянно ощущая «дескриптивно конечный характер объективности» [14, с.299].

Но в настоящее время метафизический меч, висящий над головой человечества, имеет совершенно иной характер, уверено провозглашает немецкий философ. Суть опасности, подстерегающей индивида, находится в том мире, который он искусственно создал сам для себя, но там же он себя, свою сущность и потерял. Немецкий мыслитель задается вопросом: «Что необходимо челове- 
ку, чтобы попытаться обрести самое себя? Одного лишь желания (хотя это уже много), но явно недостаточно». Немаловажное значение для Ясперса играет ощущение радости, получаемое от процесса жизнедеятельности. Но это - всего лишь островок, к которому можно приплыть в минуты боли и разочарования. Но такое прибежище имеет временный, ограниченный характер. Вечно жить в нем, спасаясь от невзгод, не представляется возможным, утверждает философ. Рано или поздно жесткая реальность накроет своим покрывалом.

В условиях современной действительности, как замечает Б.В. Марков, большую надежду Ясперс возлагает «на духовно-дружеские связи, на укорененность в почве, на дом и семью, как опоры нового порядка» [6, с.180]. Семейные отношения, по мнению Карла Ясперса, строятся на любви, взаимоуважении и верности. Именно семья связывает индивида с другими индивидами на продолжительный период времени. Это обуславливается повседневным общением, «которое способно осуществиться полностью в своей открытости только в повседневной трудности будней» [15, с.325]. В семейных отношениях, согласно Карлу Ясперсу, «истинное самобытие» приоткрывает свой лик в большей степени, так как общение осуществляется между близкими людьми, каждый день и на основе доверия, теплоты и человечности. Искренность, симпатия, тепло в людской массе рассеяны, не имеют конкретного адресата. В то время как все вышеперечисленные качества аккумулируются вокруг ограниченного количества людей, в семье, в доме, как прибежище любви и истинной дружбы. Все члены семьи для каждого конкретного индивида должны представать только в качестве субъекта, наполненного внутренним содержанием и имеющим глубоко личностную, индивидуальную суть, иметь только ему присущий, «неотъемлемый элемент духовно-душевного» [11, с.153]. Каждый служит для другого опорой и поддержкой, между членами семьи царит солидарность и доверительные отношения.

Как утверждает Павел Флоренский, существует четыре глагола-отражения понятия «любовь». Первое понимание связано с чувственной стороной жизнедеятельности человека, когда возникает желание «направлять на предмет всецелостное чувство, отдаваться предмету, для него чувствовать и воспринимать» [12, с. 396]. Это ощущение связано с миром страсти, чувственного желания, ревностное вожделение физического удовольствия. Второе толкование любви имеет широкое значение, как правило, противопоставляется страсти. Павел Флоренский полагает, что данное явление есть «внутренняя склонность к лицу, выросшая из задушевной общности и близости» $[12$, с. 396], выражает внутренние близкие отношения между людьми. В этом случае любящие индивиды находят удовлетворение в общении друг с другом, самонасы- щаются друг другом, это единение имеет «органический характер» [3, с. 241].

Третье отражение понятия «любовь» - это не страстное желание по отношению к другому объекту, не чувственный позыв к нему, а спокойное, непрерывное во времени чувство, что может быть показателем «вырастания личности» [8, с. 115]. Индивиды в этом случае ощущают себя тесно связанными, принадлежащими друг другу вне каких-либо условий и обстоятельств. Люди имеют единое понимание мироздания и других явлений, обретают органическую связь, понимаемую как родовую, нерасторжимую. В качестве примеров можно привести любовь родителей к детям, гражданина к отечеству. Четвёртое толкование понятия любви связано с рассудочным оцениванием индивида как субъекта, этом процессе превалирует разумное начало. Более всего возможно в данном случае употребить такие синонимы, как «уважение», способность ценить. Там, где есть потенция рассудочной оценки, чувство может быть слабовыраженным, неявным. Так как, по мнению Павла Флоренского, оценивание предполагает сравнение, то этот процесс может включать в себя акт свободной воли, избирательности.

Но, как отмечает немецкий философ, в настоящее время существует угроза разрушения брачно-семейных уз, более того «тенденции его разрушения растут с абсолютизацией универсального порядка существования» [5, с. 395]. Устрашающе холодный лик объективации проглядывает тогда, когда дом перестает быть оплотом любви и дружбы, залогом настоящего общения, а превращается лишь в место для ночлега. Это объясняется все большей занятостью человека на работе, недостатке свободного времени, а также растущей тенденцией технизации, что «...превращает одухотворенный мир в безразличную взаимозаменяемость» В большинстве случаев система, выступающая в качестве насилующей внешней силы, способствует разрыву или ослаблению семейных отношений, как между супругами, так между родителями и детьми, что представляет собой, по словам Р. Сафранского, опасную угрозу «заслонить собой бездну бытия» [8, с. 58]. Роль системы двояка. С одной стороны, она как будто бы поддерживает стремление индивидуумов к совместному проживанию и тесному общению. С другой, ее наличие обуславливает вероятность восстания, конфликтов, разрывов и ссор внутри семьи, даже уход из нее некоторых членов. По-сути, это обусловлено одним фактором, как считает Карл Ясперс. Действие системы таково, что в ее задачи входит не дать личности почувствовать свою великую силу над насилующей действительностью, что может найти свое проявление либо в ощущении крайнего, остро переживаемого одиночества, либо, наоборот, в чувстве сильнейшего и глубочайшего единения с другой личностью, когда человек «...выходит из темноты,...из состояния потерянности, в котором он безнадежно смотрит в пустоту, из состоя- 
ния самозабвения...» [9, с. 123]. В обществе создаются детские сады, школы и прочие социальные институты, где домашнее воспитание заменяется на публичное, где основной целью становится не воспитание единичной, единственной в своем роде, неповторимой и ни с чем несравнимой экзистенциальной личности, а механическое взращивание несметного царства себеподобных. К. Ясперс в данном контексте негативно оценивает роль государства. Вместо того чтобы запретить, а в противоположном случае строго карать за развод, полигамные отношения, аборты, гомосексуализм (все вышеперечисленное философ называет «выходом за пределы исторического существования человека»), роль государства сводится к их явному или скрытому поощрению.

Скрепами двойного толкования объединяется человеческое общество, и с точки зрения Павла Флоренского. Первая ипостась такого объединения - это личная связь, идущая от одной человеческой личности к другой, стремление уделить другому «от полноты своей» [10, с. 238]. Эта связь опирается на ощущение друг друга как самобытных единиц, «монад» [7, с. 410]. Вторая составляющая - чувство любви, симпатии по отношению к одному человеку проецируется на все общество в целом. Мыслитель отмечает, что связующими элементами античного общества были личное и родовое начало в индивиде. Обе силы с течением времени одухотворяются, превращаясь в приятельство и дружбу между членами данной общности. Существует две стороны общественной жизни, понимаемой с религиозной точки зрения: агапическая и «филическая» [4, с. 411]. Братство и дружба, по Флоренскому, находятся в параллельных друг другу областях. Может показаться, что эти два явления, как два потока, могут слиться в одно семантическое целое. Сочетание этих двух понятий являет собой двуединство, но не смешение, не отождествление.

С точки зрения Павла Флоренского, каждый человек приходится другому человеку ближним, но не всякий является другом. Неприятель, ненавистник, обидчик, клеветник ни смотря ни на что является ближним, а вот человек даже симпатизирующий, любящий не всегда есть друг в глубоком понимании Флоренского, так как отношения дружбы являются глубоко личными, индивидуальными. Наличие братьев не устраняет возможности наличия друга. В некоторых случаях наличиствование братьев делает еще острее необходимость друга. «Чтобы жить в среде братьев, надо иметь Друга, хотя бы далёкого; чтобы иметь Друга, надо жить в среде братьев», - пишет Павел Флоренский [10, с. 412]. Соблюдая «золотое правило морали» и относиться к другим как к самому себе, следует хотя бы в одном человеке «разглядеть», почувствовать, признать, «осязать» самого себя. В этом случае данный индивид и является другом, характер отношения к которому может иметь агапическое, жертвенное начало. Но чтобы потенция любви к ближнему не переродилась в самолюбование, самолюбие, чтобы индивиды не стали друг для друга просто условиями комфортного сосуществования, необходимо «развертывание» человеческой личности, ее способность к лишению эгоистических проявлений в себе, потенция агапической любви.

В том случае, если «субстанция целого» Ясперса подвергается возможности распадения, раскалывания, ее существование становится зыбким и сомнительным, сути воспитательного процесса тоже угрожает раздробление и распад на составные, не связанные друг с другом, хрупкие элементы, что приводит к появлению «изолированных индивидов» [5, с. 110]. При таких обстоятельствах воспитание как метафизически-глубокое явление не в состоянии привести становящегося индивида к постижению, всеохвату «субстанции целого», к пониманию его величия и красоты. Вместо ожидаемого появления уникального, неповторимого экзистенциального субъекта получаются многочисленные, повторяемые, малоотличимые друг от друга объекты, неспособные к установлению глубиной связи между собой. Через суть посредственности механически существующего объекта происходит то, что «субстанция целого» теряет яркую палитру красочности, метафизическую глубину сама по себе, что, по К. Ясперсу, является «симптомом обеспокоенности нашего времени» [5, с. 110]. Существующий миропорядок все более и более охватывает сомнение, разложение, распад. Создаются такие условия жизни, когда «человек может прийти к иному сознанию бытия и самого себя» [13, с. 377], - замечает мыслитель. Перед ним как будто бы разверзается зияющая черная бездна, в которую он вот-вот сползет, захватив с собой всех людей. Мыслящие и чувствующие индивидуумы предчувствуют приближение мертвящих шагов безжалостной бездны, способной поглотить величие и красоту «истинного самобытия». Немецкий философ уверенно утверждает, что решение данной проблемы ложится на плечи воспитания грядущих поколений. Он пишет следующее: «... воспитание определяет будущее человеческое бытие; упадок воспитания был бы упадком человека» [5, с. 353].

«Для того, чтобы быть самим собой, - пишет Карл Ясперс, - человек нуждается в позитивно наполненном мире» [14, с. 399]. Если мир не таков, то человек прячется от него до тех пор, пока не обретет положительно окрашенную мысль или идею. Сначала изменения, пусть даже весьма несущественные, происходят в глубине человеческой личности, а лишь за тем переносятся на существующий миропорядок. Если вдруг явленное бытие предстанет перед лицом индивида в неприглядном, отталкивающем виде, в этом случае цель его - сохранить в себе то положительное, что успел накопить. Некоторые сегодня с отчаянием задают вопрос: что же осталось теперь в мире, чем стоит дорожить, на что надеяться, ради чего быть? Ответ философ дает следующий: самое драгоценное, кла- 
дезь неисчерпаемых возможностей - это человек, взятый в «подлинном самобытии» или, по словам И.Н. Сидорова, «необъктивируемость, ... неэмпирическую целостность, представленную душой человека» [9, с. 78]. «Духовная ситуация требует сегодня сознательной борьбы человека, каждого человека за его подлинную сущность. Он должен устоять в этой борьбе или быть побежденным, и это зависит от того, насколько он уверен в основе своего бытия в действительности своей жизни», - пишет Карл Ясперс.

\section{Зак^ючение}

Ощущение единства между людьми Павла Флоренского и Карла Ясперса проникает во все сферы жизнедеятельности, в том числе, в повседневную жизнь, «озолачивает каждодневное» [12, с. 413]. Понятие друга становится чем-то большим, «ценной величиной» в условиях со-работничества, со-товарищества.

Карл Ясперс и Павел Флоренский в рамках идеи единения большое внимание уделяют процессу воспитания личности. По их мнению, воспитание - это «глубокий процесс, порождающий бытие человека» [6, с. 393]. Посредством воспитания происходит становление человека. Здесь имеется в виду не только генетическое наследование, но передача в первую очередь социально-исторического опыта предшествующих поколений. Под воспитанием философ понимает не только непосредственное воздействие на индивида родителей или школы, а то, что он слышит, видит, узнает в течение своей жизнедеятельности, и это в последствии становится как бы его второй натурой. Таким образом, понимаемое воспитание делает конкретную человеческую личность соучастником бытия, или посредством его существования - «соучастником в знании целого» [6, с. 353]. Вместо того, чтобы неподвижно пребывать, человек привходит в мир, становится его участником и соучастником. В данном случае, не смотря на ограниченную узость бытия индивида по сравнению с неохватной шириной бытия в целом, первое может быть воодушевлено и обогащено до предела вторым. Человек тем решительнее может стать самим собой, чем ярче, красочнее, наполненнее миропорядок, с которым его собственная суть вступает в контакт и составляет определенное единство. Главная цель осуществления воспитательного процесса, согласно взглядам Ясперса и Флоренского, заключается в том, чтобы новое поколение каждый раз втягивалось в дух целого. Задача воспитателя, учителя - служение «...потоку становления человеком, который протекает в равномерности уверенного континуума» [10, с. 400].

\section{ЛИТЕРАТУРА}

1. Визгин, В.П. Лица и сюжеты русской мысли: сборник научных трудов / В.П. Визгин. - Москва: Языки славянской культуры: Фонд Развития Фундаментальных лингвистических исследований, 2016. - 360 с.

2. Власова, 0.А. Теория и терапия кризиса: от критики культуры к практике саморазвития. Вестник ВГУ. Серия: Философия. 2018 . № 4.

3. Водолагин, А.В. Философия и психопатология: творчество Карла Ясперса // Вопросы философии. № 4. 2006.

4. Звейрде, ван дер э.. Взгляд со стороны на историю русской и советской философии / Звейрде, ван дер Э.; науч. ред. П.В. Аракчеева, А.Л. Доброхотов. Санкт-Петербург: Алетейя, 2020. - 556 с.

5. Золотухина-Аболина, Е.В. Бытие человека: ключевые экзистенциалы / Е.В. Золотухина-Аболина. - Москва; Берлин: Директ-Медиа, 2017. - 220 с.

6. Марков, Б.В. Коммуникация, феноменология и экзистенция: К. Ясперс и М. Хайдеггер. История современной зарубежной философии: компаративистский подход / [А.С. Колесников, М.Я. Корнеев, Б.В. Марков и др.] - СПб.: ЛАНЬ, 1997.

7. Павлюченков, Н.Н. Религиозно-философское наследие священника Павла Флоренского: антропологический аспект / Н.Н. Павлюченков; Православный Свято-Тихоновский гуманитарный университет. - Москва: Православный Свято-Тихоновский гуманитарный университет, 2013. - 288 с.

8. Сафрански, Р. «Вольные вариации на тему свободы». Позиции современной философии. Альманах кафедры современной зарубежной философии философского факультета Санкт-Петербургского государственного университета и Проблемного совета по современной зарубежной философии. - СПб.: Изд-во С.-Петерб. Ун-та, 2004.

9. Сидоров, И.В. К. Ясперс: предэкзистенциализм и экзистенциализм. История современной зарубежной философии: компаративистский подход / [А.С. Колесников, М.Я. Корнеев, Б.В. Марков и др.] - СПб.: ЛАНь, 1997.

10. Флоренский, П.А. Том 1. Столп и утверждение истины / П.А. Флоренский. - Москва: Комсомольская правда, 1990. - Ч. І. - 496 с.

11. Ясперс, К. Введение в философию / Пер. с нем. Под ред. А.А. Михайлова. - Мн.: Пропилеи, 2000.

12. Ясперс, К. Введение в философию / Пер. с нем. Под ред. А.А. Михайлова. - Мн.: Пропилеи, 2000. Степанович, В.А. История философии: курс лекций: в 2 томах / В. А. Степанович. - Москва: Прометей, 2018. - Том 2. Неклассическая философия XIX-XX веков.

13. Ясперс, К. Введение в философию / Пер. с нем. Под ред. А.А. Михайлова. - Мн.: Пропилеи, 2000.

14. Ясперс, Карл Теодор. Духовная ситуация времени. Пер. с нем. - М.: АСТ, Neoclassic, 2013.

15. Ясперс, Карл. Ницше. Введение в понимание его философствования / К. Ясперс; пер. с нем. Ю. Медведева; под ред. М. Ермаковой. - СПб.: Владимир Даль: Фонд «Университет», 2004. 